\title{
Design of Mobile Learning Platform of Cadre Training Based on Big Data Environment
}

\author{
Yunke Zhou
}

Hainan Radio and TV University, Haikou, Hainan, 570208

Keywords: cadre training platform; mobile learning platform; big data environment

\begin{abstract}
Network education has the characteristics of time and space separation, rich resources and convenient use. It is the mainstream and direction of the development of cadre training. With the continuous development of the cadre network education platform, the frequency of use is getting higher and higher, and the generated data is getting bigger and bigger. This "big data" implies the knowledge level, work field, interest, focus information and other information. Through the analysis of big data, it can be found that the imperfect learning resource evaluation mechanism, the excessively extensive supervision of the learning process, and the quantitative analysis of the learning effect neglected are the main problems faced by the development of cadre network education. To break through this dilemma, it is necessary to further improve the top-level design of the platform, the sharing of resources, the promotion of learning resources, and the evaluation of refinement effects, so as to promote the setting of online learning courses and learn interactive experiences, stimulate the interest of cadres to learn independently, and promote the continual and healthy development of cadre network education.
\end{abstract}

\section{Introduction}

With the continuous innovation and research and development of China's current mobile communication terminal technology, the scale of use of mobile phone users is constantly expanding, and the mobile phone operating system is also being used more diversely. The main function of the mobile phone is that it has strong portability and can be used more easily and conveniently without time and space restrictions. Then in order to further meet the diverse functional needs of the students based on Android. This research explores a series of development implementations on the Android platform for mobile learning systems. The mobile learning platform can maximize the learning needs of users anytime and anywhere, and complete the learning of multiple test questions online, realize mobile reading and online test communication, etc., greatly improving the overall efficiency of learning. The mobile learning platform mainly includes two parts of the function: mobile learning function and mobile management mode. Due to the software and hardware related performance of mobile devices, compared with PC devices, the original network teaching resources can no longer be applied to new mobile devices. Therefore, the current Android-based mobile device learning platform resources are scarce, so how effective The design and development of Android's cadre training mobile learning platform is an important research topic nowadays.

\section{The Dilemma Faced by the Development of Cadre Network Education Platform}

Due to the short history of the network education of party members and cadres in China, many aspects are still in the exploration stage, and there are not many mature experiences. The development of foreign civil servant network education is ahead of China, but the education mechanism and goal of civil servants in developed countries are different from those in China. We can only learn some useful experiences by "taking the rough and fine" and cannot completely copy the foreign theory. It should be said that a strong research team has been formed in distance education and online learning research in China, and some achievements have been made. However, cadre online education is different from general online education and has its own characteristics. Therefore, we can only analyze and grasp the characteristics of cadre network education and 
establish a theoretical research system in line with cadre network education. On the CNKI platform, the search of related keywords of cadre network education can be found that there are still three shortcomings in the current research work: First, the research team has not yet formed. Research authors are scattered, and few authors continue to conduct in-depth research in this field. Second, the depth of research is not enough. Cadre network education does not form its own discourse system, and some only copy the theory of foreign research or the theory of distance education. There are few online education theories that are characteristic of cadre education. Third, the research method is single. There are many reviews or simple arguments, few research and empirical studies, and theoretical research lacks data. Practice has proved that without the support of theoretical research, the platform has no vitality; without the practice and results of the platform, theoretical research can not find a direction.

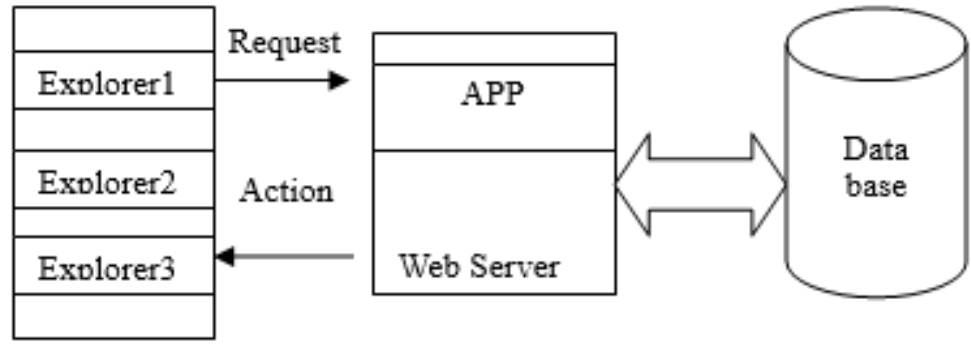

Fig 1. System Working Structure

Learning resources are the basis for ensuring the normal occurrence of online learning. The quality resources can stimulate the internal learning motivation of students and improve the learning effect. Therefore, from the production, application, evaluation and regeneration of learning resources, we need to pay attention to. The learning resources on the cadre network education platform are mainly generated through the organization of the department, the production of the party school or the administrative college, and the recommendation of the university's excellent courses. The cadre network education platform has put forward its own requirements for the format and standard of learning resources. For example, the "China Cadre Network College" has given guiding opinions on the quality standards of the excellent curriculum, and put forward specific requirements on the format, quantity and size of the documents. . However, the inconsistency in the production standards, production frameworks, and playback tools of the various platform learning courses has made it difficult for resources to be shared among platforms. In addition, the learning resources on the cadre network education platform are mainly evaluated by professionals and determined resource levels, and most of these evaluations focus on information technology and multimedia production. In this regard, Kang Xiaowei, Lin Bo et al. proposed that the network learning resources are gradually transferred from the kernel to the extension according to knowledge. The three dimensions of learning resources, learning resource transformation process and learning support system should be selected for evaluation; Yong proposed that the evaluation index system of digital learning resource quality mainly includes four aspects: resource content, resource organization form, resource support system and resource use performance; Huang Kebin proposed that developers, users and reviewers of online education resources And the manager is the subject of evaluation. From the above point of view, it can be seen that the evaluation of e-learning resources includes not only the form of resource organization but also the content of the resource itself. Therefore, this requires the participation of subject professionals in the evaluation. More importantly, the resource use performance learners have the most say, especially the extensive evaluation of the students. In fact, the network education platforms of major cadres have used the new quantity of resources as the evaluation index of the platform. It is only the consensus at the beginning of the platform construction. However, when resources are accumulated to a certain extent, it is difficult for students to find targeted resources in a variety of resources. Content, a lot of learning is required to find the most exciting ideas and evaluations, which is not expected at the beginning. This is resource redundancy for the students. Only by regenerating the essential resources can the students' self-study enthusiasm be stimulated. 


\section{The Path of the Development of Cadre Network Education Platform under the Background of Big Data}

At present, the cadre network education platform has a wide coverage, many levels of training objects, and difficulty in organization and management. Therefore, it is necessary to do a good job in the top-level design of the four levels of organization, resources, processes and technology. At the organizational level, in order to implement the "teaching, learning, management, and examination" links, a provincial, municipal (state), county (city, district) three-level educational organization service system should be established; at the resource level, with advanced experience, Establish a standard framework system for resources, a review mechanism for resources, and a resource sharing mechanism between platforms. At the process level, it is necessary to focus on cadre students and plan a complete learning process according to the teaching methods such as special study, organizational learning, and self-selection. , divide learning nodes, plan learning support service methods; At the technical level, adopt international standard common technology, support cross-platform deployment, support multiple data exchange and sharing methods, support multi-user number and high concurrency.

The Modern Distance Education Standardization Committee has proposed a relatively complete Chinese online education technology standard architecture and produced 11 specifications. This set of standards is not only the basic technical specification for the development of network education systems, but also a reference specification for the development of various other teaching application systems under network conditions. As the current foreign learning resource standard, the SCORM standard is that the teaching materials can be cross-platform through a unified format, which can be truly reusable. The tracking learning records can also have a unified standard, which can meet the needs of learners. In addition, advocacy The granulation of the course, the separation of the learning content and the learning platform, can reduce the difficulty of making online courses. It is recommended that the cadre network learning platform resource construction follow the SCORM standard to facilitate the sharing and sharing of resources. The construction of cadre network learning resources should adapt to the needs of current leading cadre training, insist on putting the content of new theories, new knowledge and new practices in the first place, and update the curriculum resources in a timely manner. New issues, new perspectives, and new resources will trigger the students' interest in learning. In addition to the new curriculum resources, the essence and exquisite parts of the original curriculum are also the focus of the students' learning and attention. Therefore, it is necessary to carry out evolutionary research on this part of the resources. The evolution of learning resources is the improvement and adjustment of the content and structure to meet the various dynamic and personalized learning needs of learners, so as to constantly adapt to the changing learning environment.

At present, the availability of resources cannot meet the needs of the students. The key is not to do a good job in resource evaluation. The current curriculum resources are mostly presented to the trainees in the form of networks, and the evaluations are mostly conducted in the form of feedback. The form is single and not explicit, which will hinder the scientific nature of resource evaluation and reduce the availability of resources. In order to ensure the scientific and effective evaluation of cadre network learning resource quality, a combination of expert evaluation and student evaluation should be adopted. Expert evaluation should establish an evaluation team that includes a wide range of professionals. It should usually include subject (domain) experts, educational technology experts, multimedia designers, resource managers, etc. Expert evaluation should take into account the evaluation of technical evaluation, functional evaluation, and performance. . Participants can use quantitative indicators and social tags (tag tags). Quantitative indicators are metrics that are common to the course, such as whether the course is organized, whether the arguments are clear, whether the form is appropriate, etc., so that the students can score or give a grade; the social tag can define multiple subordinate categories, reflecting the user's initiative. Participation and the attention of network users, so that the social hotspots are simply mapped. On the one hand, students can tag the resources or content they have learned to improve the accuracy and intelligence of resource search. On the other hand, the Tag tag can also be used as a link to identify interest groups 
and explore with other students. The subject of interest. Finally, the results of the expert review should be combined with the total score of the student's evaluation as the main basis for determining the quality evaluation level of the network learning resources.

\section{Conclusion}

With the development of mobile terminals, wireless communication technologies, 3G, 4G technologies, a new form of learning, mobile learning, has emerged in the field of education and training. Because mobile learning has the characteristics of learning convenience, context relevance, mobility, fragmentation and ubiquity, it determines that it is the main direction of future education and training. It should be pointed out that the mobile learning platform is not a simple copy of the cadre network education platform to the mobile terminal, but requires the parallel development of mobile learning theory research and the construction of the mobile learning platform: First, the age level of mobile users and the way of using preferences The single-use time, etc., are all factors to be considered in the mobile learning platform. Secondly, the mobile terminal device has its own characteristics in terms of screen size, resolution, and capacity for accommodating text. Therefore, the provision of mobile learning resources requires detailed planning and research by professionals.

\section{Acknowledgements}

Fund Project: 2017 Hainan Provincial Higher Education Research Funding Project (Project No.: Hnky2017-56)

\section{References}

[1] Yan Hongwei. Discussion on online education mode of cadres in the new media era [J]. Industry and Technology Forum, 2017, (11).

[2] Kang Xiaowei, Lin Bo. Research on the evaluation of online learning resources based on colleges and universities [J]. Research in Audio-Visual Education, 2016, (6).

[3] Wan Liyong. Research on quality evaluation of digital learning resources [J]. Modern Educational Technology, 2013, (1).

[4] Huang Kebin. Research on the evaluation of network education resources [J]. Modern distance education research, 2005, (5).

[5] Lu Qiuli, Wei Shunping. Investigation and analysis of network education resource standards and standards application [J]. China's electrification education, 2015, (7). 